\title{
Comparative Studies on Salivary Kallikrein from Cystic Fibrosis Patients and Controls
}

\author{
ESTER R. HARE AND JACOB A. VERPOORTE \\ Department of Biochemistry, Dalhousie University, Halifax, N.S. Canada B3H $4 H 7$
}

\begin{abstract}
Kallikrein (EC 3.4.21.8) has been purified from the saliva of cystic fibrosis (CF) patients and from healthy individuals. The yields of enzyme are the same for both kinds of saliva. The CF and normal kallikrein have similar physical-chemical properties, such as amino acid composition, electrophoretic mobilities in polyacrylamide gels when different conditions are used, intrinsic fluorescence, and circular dichroism. The enzymes have no $\alpha$ helix structure but large amounts of pleated sheet structure. CF and normal salivary kallikrein have also similar enzymatic properties, for example both enzymes show maximum activity at $\mathrm{pH} 8.2$. An identical value of $\mathrm{K}_{\mathrm{m}}=$ $0.4 \mathrm{mM}$ has been found for both enzymes with $\mathrm{N}$-benzoyl arginine ethyl ester as substrate, despite the fact that the kallikreins are inhibited by high substrate concentrations. The results of this investigation show that the salivary kallikrein in CF is normal and that it has normal activity. This leads us to suggest that the salivary kallikrein is not the cause of the observed abnormalities in CF saliva. (Pediatr Res 19: 938-943, 1985)
\end{abstract}

\section{Abbreviations}

BALE, N-benzoyl arginine ethyl ester

BP'II, bovine pancreas trypsin inhibitor

(I), circular dichroism

( $\mathrm{F}$, cystic fibrosis

IIPIC, high performance liquid chromatography

pl, isoclectric point

sids, sodium dodecylsulfate

Abnormal secretions have been recognized for some time as one of the basic abnormalities in patients with $(\mathrm{f}:(1,2)$, for example the elevation of sodium levels in secretions is a consistent linding in ( 1 : (3).

Salivary glands secrete an isotonic solution of electrolytes and macromolecules, but during its passage through the glandulat ducts ions are reabsorbed and the solution becomes hypotonic Dann and Blatu (4) suggested in 1978 that the reabsorption of ions in glandular ducts is controlled by arginine esterases which are present in the glands. At the same time they proposed that abnormal clectrolyte concentrations in ( $\mathrm{I}$ secretions are caused by a deficiency in either the glandular kallikrein, which itself has arginine esterase activity, or in some other arginine esterase. In 1981 Hallinan (5) expanded this hypothesis and proposed that ( 1 : could be due to a possible defect in an intracellular enzyme, which carries out an as yet unk nown but functionally important

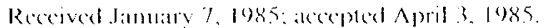

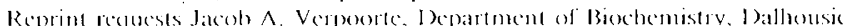

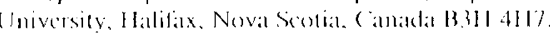

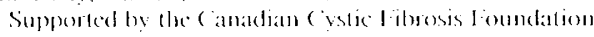

posttranslational modification to the arginine esterases, for example a glycosylation or phosphorylation.

Catanzaro et al. (6) demonstrated in 1978 that kallikrein is involved in the control of $\mathrm{Na}^{+}, \mathrm{K}^{+}$, and $\mathrm{H}_{2} \mathrm{O}$ secretions in the saliva of the rat. Subsequently it has been shown that kinins, which are small peptides that are produced by kallikrein through cleavage of kininogens, are directly involved in the inhibition of electrolyte absorption in guinea-pig ileum (7). Because of these findings it was decided to study the kallikreins in normal and $\mathrm{CF}$ saliva and to investigate whether the hypothesis of Dann and Blau (4) or that of Hallinan (5) is correct.

The isolation of human salivary kallikrein has been reported by Fujimoto et al. (8) and by Modeer (9). More recently Hoffman et al. (10) isolated this enzyme by selective catheterization of glandular ducts while Wong et al. (11) purified the enzyme from parotid saliva. However, significant differences have been reported in the properties of the purified salivary kallikreins, for example in isoelectric focusing and molecular weights. We have therefore recently developed a new method to purify kallikrein from human whole saliva. Several properties of the purified kallikrein from the saliva of CF patients will now be reported together with those of the normai kailik rein that have not ieen previously reported.

\section{MAITRIAIS ANI) MIIIIOISS}

Whole saliva, stimulated by chewing dental wax (c ybron/ Kerr) was obtatned from both male and lemale volunteers. 1 he ( 1 patients were in the age group between 18 and $25 \mathrm{yr}$. They were all diagnosed at a young age with the sweat-test and they have been under regular observation in the (I-clinic at the I.W.K. I Iospital for (hildren in I Jalifax, N.S. Canada, which is under the direction of I)r. ('. T. (iillespie. The patients were mostly university students and were considered to be in good condition. They produced each about $150 \mathrm{ml}$ saliva per turn and the saliva of three to four patients were pooled to give a volume of about $500 \mathrm{ml}$. The pooled samples consistently contained higher concentrations of protein, carbohydrate, and nondialyzable compounds, than normal saliva.

A Spherogel-TSK 3000$) \mathrm{SW}$ column $(7.5 \times 300 \mathrm{~mm})$ was purchased from Beckman Instruments for use in IIPI. ${ }^{\circ}$

The synthetic substrate $\mathrm{B} \wedge \mathrm{II} \mathrm{I}$ and trypsin inhibitors were obtained from sigma.

The purification procedure for salivary kallikrein is described elsewhere (12). The same procedure was used for normal and ( li salivat.

Protein determinations were done with (oomassie Blue by the Bio-Rald method (13) and a protein standard, purchased from Bio-Rad, was included in each determination. Inzymatic activity was determined with $B \wedge \mathrm{I} \mathrm{I}$ as substrate and the reaction was monitored at $253 \mathrm{~nm}$ (14) with a (ary 14 recording spectrophotometer.

(iel electrophoresis has been done as described elsewhere (12) and the molecular weights of the salivary kallikreins were calcu- 
lated from their mobilities in the SDS containing gels using a reference mixture of standard proteins (obtained from Pharmacia). Isoelectric focusing was done using a LKB 8101 column ( $\mathrm{LKB}$, Sweden). The $\mathrm{pH}$ gradients were formed with Pharmalyte pH 2.5-5.0 in sucrose density gradients.

Amino acid analyses were done with a Beckman model 6300 analyser after hydrolysis of the enzymes in $6 \mathrm{M} \mathrm{HCl}$. Separate samples were oxidized with performic acid at $2^{\circ} \mathrm{C}$ for $4 \mathrm{~h}$ and then analyzed for cysteic acid and methionine sulfone (15). Tryptophan was determined by the method of Goodwin and Morton (16).

Fluorescence measurements were made with an Aminco-Bowman spectrofluorometer at room temperature, using a $3 \mathrm{~mm}^{2}$ cuvette which requires only $100 \mu$ l of solution. The spectra were corrected as outlined by Melhuish (17) and a horizontally oriented polarizer was used in the excitation beam to reduce scattering (18). The corrected intrinsic fluorescence spectra were analyzed to determine the number of independent fluorescent components (19).

Circular dichroism spectra were measured at wavelengths below $240 \mathrm{~nm}$ with a Cary 6001 instrument. The data were converted to $\mathrm{deg} \cdot \mathrm{cm}^{2} \cdot \mathrm{dmol}^{-1}(20)$ using a mean residue weight of 107 as calculated from the amino acid composition. The secondary structures were computed using the method of Chang et al. (20), who also provided us with the four reference spectra, e.g. those for $\alpha$-helix, pleated sheet, $\beta$-turns, and unordered structures. The following constraints were used: (1) none of the aforementioned structures could be present in the protein at more than $100 \%$ or less than $0 \%$, and (2) the sum of the four structures must be $100 \%$.

\section{RESULTS}

The flow chart illustrated in Figure 1 summarizes the procedure for the purification of a salivary BAEE-esterase from either CF patients or normal individuals. It has previously been shown that a partially purified BAEE esterase from normal saliva produces kinins in acid-treated dog plasma (21). The same enzyme also reduces the blood pressure of a rabbit when injected intravenously. This enzyme therefore seems to belong to the glandular kallikreins.

Affinity chromatography on BPTI-Sepharose gives the greatest increase in purity in a single step, but it fails to remove an inactive protein component from the enzyme. Complete purity of the enzyme is not obtained until after HPLC on a SpherogelTSK 3000 SW column (see Fig. 2). HPLC separates two protein components, but only the material that elutes between 21 and 24 min contains enzymatic activity, the other component is completely inactive. The inactive component is present in normal and in CF saliva and appears to bind to the kallikrein because it does not itself show affinity for the BPTI-Sepharose column.

The saliva of $\mathrm{CF}$ patients contains similar BAEE esterase activity as saliva of normal controls. Examples of the purification of kallikrein from saliva are shown in Table 1. Understandably the data fluctuate between different batches of saliva but the

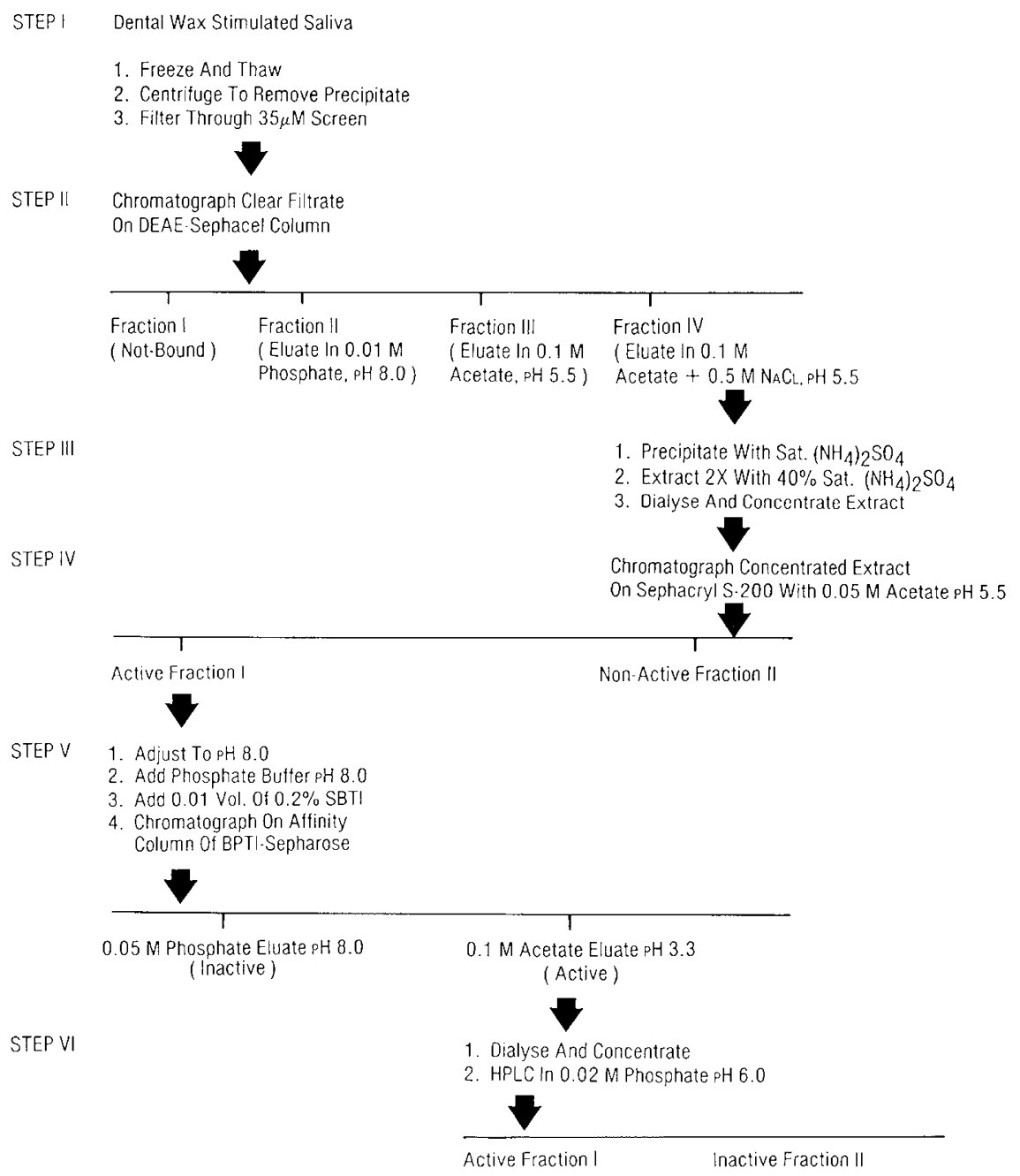

Fig. 1. A flow chart illustrating the purification of kallikrein from whole saliva. 
results shown in Table 1 are quite typical. It can be seen that the final purification of the CF kallikrein and its activity are the same as that for the normal enzyme, and this purification as well as the yield does not vary more than $10-20 \%$ from batch to batch.

Polyacrylamide gel electrophoresis experiments at $\mathrm{pH} 9.5$ and at $\mathrm{pH} 8.2$ in the presence of SDS, show that the CF enzyme has normal mobilities (see Fig. 3). The molecular weights have been determined from the mobilities in the SDS containing gel and a value of 40,000 has been calculated for both normal and $C F$ salivary kallikrein.

The amino acid compositions of the enzymes are shown in Table 2 . The compositions are very similar. Both enzymes contain a large number of aspartic and glutamic acid residues and only small numbers of the various basic residues. The $\mathrm{pI}$ values of the salivary kallikreins have also been determined by isoelectric focusing and as anticipated from the amino acid compositions, low values, $\mathrm{pI}=4.00 \pm 0.08$, have been found. The methionine and cysteine contents of both enzymes are very low and an accurate determination of these residues proved to be almost impossible. Slight discrepancies have been observed for the proline and valine residues but otherwise the amino acid contents are the same within I SD $(n=4)$.

Normal and CF salivary kallikrein each contain 1 mol percent of tryptophan whose presence has also been demonstrated by measuring the intrinsic fluorescence spectra. The corrected excitation spectra of both enzymes at $\mathrm{pH} 7.0$ show a maximum at $282 \mathrm{~nm}$ while the corrected emission spectra show a broad peak centered at $338 \pm 1 \mathrm{~nm}$ (see Fig. 4). The fluorescence intensities at $338 \mathrm{~nm}$ are the same for normal and CF enzyme solutions after correcting for the difference in absorbances at $275 \mathrm{~nm}$. An algebraic method was used to analyze the emission spectra obtained at four different wavelengths of excitation, and it was

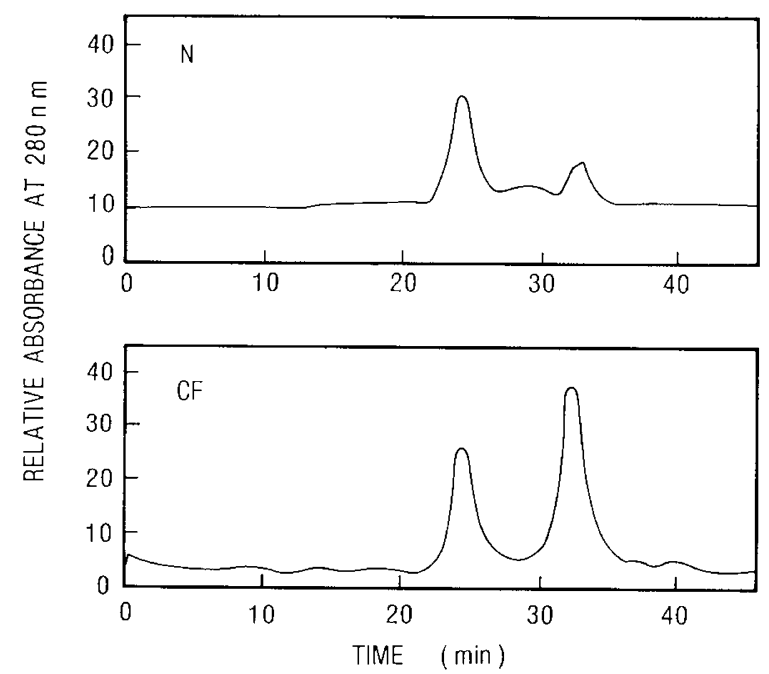

Fig. 2. HPLC of normal and CF kallikrein on a Spherogel-TSK 3000 SW column $(7.5 \times 300 \mathrm{~mm})$. The flow rate was $0.6 \mathrm{ml}$ of $0.01 \mathrm{M}$ phosphate $\mathrm{pH} 5.6$ per min at room temperature. found that two independent groups contribute to the intrinsic fluorescence of normal and CF kallikrein. These groups are presumed to be tyrosine and tryptophan.

The CD spectra of the salivary kallikreins are shown in Figure 5. Both spectra show a maximum negative ellipticity at $197 \pm 1$ $\mathrm{nm}$ with values of $[\theta]=-12,000 \pm 1,300 \mathrm{deg} \cdot \mathrm{cm}^{2} \cdot \mathrm{dmol}^{-1}$. The curves were analyzed with a computer using four basic reference spectra, and the results are shown in Table 3. It can be seen from Table 3 that the salivary kallikreins have no $\alpha$-helix structure. On the other hand, the enzymes have substantial amounts of pleated sheet structure. The data of Table 3 have been used to calculate the best fit of the observed spectrum for normal kallikrein (see Fig. 5). This computed curve resembles, but does not exactly fit, the observed spectrum.

The enzymatic properties of the CF salivary kallikrein have been investigated and compared with those of the enzyme obtained from control saliva. Neither enzyme cleaves azocasein nor are they inhibited by soybean or lima bean trypsin inhibitors. On the other hand, both enzymes are inhibited by BPTI and also by di-isopropyl fluorophosphate. As shown in Table 4 the enzymes also reduce the blood pressure of a rabbit when injected intravenously. When 10 micrograms protein, corresponding to $20-25 \mathrm{ml}$ saliva, is injected the rabbit's blood pressure is reduced by about $10 \mathrm{~mm} \mathrm{Hg}$.

The $\mathrm{pH}$ rate profiles for normal and CF salivary kallikreins are shown in Figure 6. It can be seen that neither enzyme cleaves BAEE at pH values below 5.0. The activities increase rapidly above $\mathrm{pH} 6.0$ and reach maximum values at $\mathrm{pH} 8.2 \pm 0.2$. At high $\mathrm{pH}$ the enzymes remain fairly active and at $\mathrm{pH}=10.0$, for example, the activities are still about $80 \%$ of the observed maxima.

When the concentration of the substrate BAEE is increased to in excess of $1 \mathrm{mM}$, the reaction velocities begin to decrease. This substrate inhibition is observed for both CF and normal salivary kallikrein, and with freshly recrystallized BAEE. Figure 7 illustrates the double reciprocal plots of velocity versus BAEE concentration for the enzymes. These Lineweaver-Burk plots are linear if the data points at higher BAEE concentrations are ignored. By extrapolating these linear parts of the plots one obtains the apparent values for $\mathrm{Km}$ and Vmax which are shown in Table 4. From this Table 4 it is evident that the $\mathrm{CF}$ and normal salivary kallikreins have very similar kinetic parameters.

\section{DISCUSSION}

A BAEE-esterase has been purified from whole saliva from $\mathrm{CF}$ patients and controls. The demonstrated activities and biological effect of this enzyme and also the effects of trypsin inhibitors on the esterase activity, made us name this enzyme a kallikrein.

The batches of CF saliva showed often a higher viscosity than the normal batches but this did not appear to affect the purification procedure. The yield and the purification factor indicate that $\mathrm{CF}$ saliva contains a normal level of kallikrein which amounts to $0.4-0.5 \mu \mathrm{g} / \mathrm{ml}$. The most important purification step is the affinity chromatography on a BPTI-Sepharose column. However, not all the inactive protein components are removed during this step, because an inactive protein, which is rather

Table 1. The purification of salivary kallikreins

\begin{tabular}{|c|c|c|c|c|c|c|c|c|}
\hline \multirow[b]{2}{*}{ Preparation } & \multicolumn{2}{|c|}{ Protcin $(\mathrm{mg})^{*}$} & \multicolumn{2}{|c|}{ Activityt } & \multicolumn{2}{|c|}{ Yield $(\%)$} & \multicolumn{2}{|c|}{ Purification } \\
\hline & $N$ & $\mathrm{CF}$ & $\mathrm{N}$ & $\mathrm{CF}$ & $\mathrm{N}$ & $\mathrm{CF}$ & $\mathrm{N}$ & $\mathrm{CF}$ \\
\hline Whole saliva. centrifuged and filtered & 605.0 & 700.0 & 1.78 & 1.64 & 100 & 100 & 1 & 1 \\
\hline DEAE-Scphacel. fraction IV & 59.0 & 66.0 & 16.0 & 16.4 & 88 & 94 & 9 & 10 \\
\hline Sephacryl S-200 & 12.0 & 13.7 & 60.5 & 52.5 & 67 & 63 & 34 & 32 \\
\hline BPTI-affinity & 0.512 & 0.525 & 987.0 & 1017.0 & 47 & 47 & 554 & 620 \\
\hline HPLC & 0.066 & 0.053 & 4880.0 & 4760.0 & 30 & 22 & 2742 & 2902 \\
\hline
\end{tabular}

* The purification was started with $500 \mathrm{ml}$. N, normal.

+ Activity in $\mathrm{nmol} / \mathrm{min} / \mathrm{mg}$ protein. Protein was determined with the Bio-Rad method and the substrate was BAEE. 


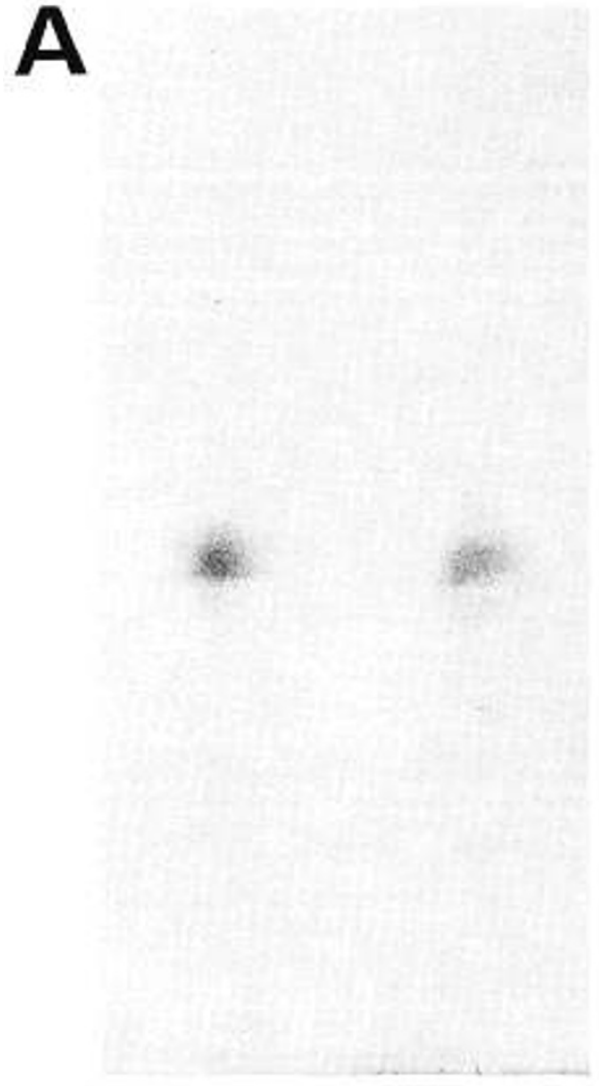

1
B

$94 K$

$67 K$

$43 \mathrm{~K}$

$30 \mathrm{~K}$

$20 \cdot 1 \mathrm{~K}$

$14 \cdot 4 K$
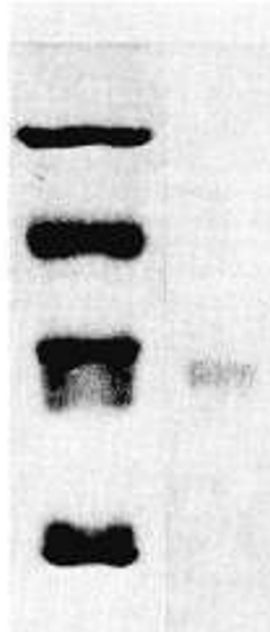

Fig. 3. Polyacrylamide gel electrophoresis of normal and CF salivary kallikreins at pH $9.5(A)$ and at pH 8.2 in the presence of SDS $(B)$. Normal enzyme in channels $\mathrm{A} 1$ and $\mathrm{B} 2, \mathrm{CF}$ enzyme in channels $\mathrm{A} 2$ and $\mathrm{B} 3$, and a mixture of callibrating proteins in channel $\mathrm{B} 1$.

Table 2. Amino acid compositions of the salivary kallikreins

\begin{tabular}{lrr}
\hline & CF enzyme* & Normal enzyme† \\
\hline Aspartic acid & $10.8 \pm 0.5$ & $10.8 \pm 0.7$ \\
Threonine & $5.3 \pm 0.3$ & $5.2 \pm 0.2$ \\
Serine & $11.5 \pm 0.8$ & $11.1 \pm 0.7$ \\
Glutamic acid & $13.6 \pm 1.7$ & $15.3 \pm 2.1$ \\
Proline & $4.7 \pm 0.7$ & $5.9 \pm 0.6$ \\
Glycine & $12.4 \pm 0.8$ & $13.3 \pm 0.8$ \\
Alanine & $6.6 \pm 0.4$ & $6.5 \pm 0.3$ \\
Valine & $6.3 \pm 0.4$ & $5.4 \pm 0.1$ \\
Cysteine & $0.7 \pm 0.4$ & $0.4 \pm 0.3$ \\
Methionine & $1.1 \pm 0.4$ & $1.1 \pm 0.4$ \\
Isoleucine & $3.0 \pm 0.3$ & $2.6 \pm 0.2$ \\
Leucine & $7.4 \pm 0.5$ & $7.6 \pm 0.3$ \\
Tyrosine & $2.4 \pm 0.4$ & $2.3 \pm 0.2$ \\
Phenylalanine & $3.7 \pm 0.3$ & $3.4 \pm 0.1$ \\
Lysine & $3.1 \pm 0.5$ & $3.3 \pm 0.3$ \\
Histidine & $2.9 \pm 0.4$ & $2.6 \pm 0.3$ \\
Arginine & $3.3 \pm 0.6$ & $2.8 \pm 0.4$ \\
Tryptophan & 1.0 & 1.0 \\
\hline
\end{tabular}

* Mean \pm 1 SEM of three determinations.

$\dagger$ The mean value \pm 1 SEM of four determinations, see Reference 12 .

proline-rich, is still present. HPLC has shown that this is the case for normal as well as CF saliva. Since this inactive contaminant does not bind to the BPTI-Sepharose column it is assumed to be associated with the salivary kallikreins, from which it dissociates at weekly acidic $\mathrm{pH}$.

The enzymes purified from $\mathrm{CF}$ and normal saliva show identical electrophoretic mobilities in polyacrylamide gels at $\mathrm{pH} 9.5$

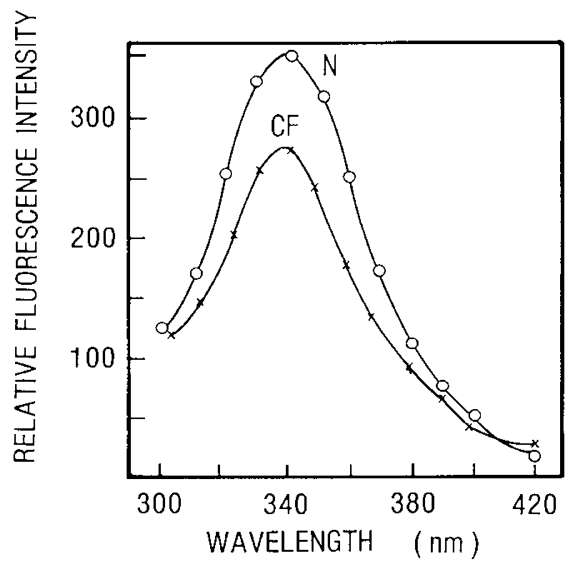

Fig. 4. Corrected fluorescence spectra of normal and CF kallikreins in $0.02 \mathrm{M}$ phosphate buffer $\mathrm{pH}$ 7.0. The wavelength of excitation was $282 \mathrm{~nm}$. The fluorescence intensities at $338 \mathrm{~nm}$ are directly proportional to the absorbances of enzymes which were 0.213 for normal enzyme and 0.164 for CF enzyme at $275 \mathrm{~nm}$.

and in gels containing SDS at $\mathrm{pH}$ 8.2. Both enzymes show only one band in either gel which proves that they are pure. The identical mobilities of the enzymes in the presence of SDS suggests that the CF kallikrein has the same molecular weight of 40,000 as the normal enzyme. The latter's molecular weight has previously been confirmed by sedimentation equilibrium (12).

The amino acid compositions of CF and normal kallikreins are very similar. Both enzymes have high contents of acid residues while the basic amino acid residues are only small in 


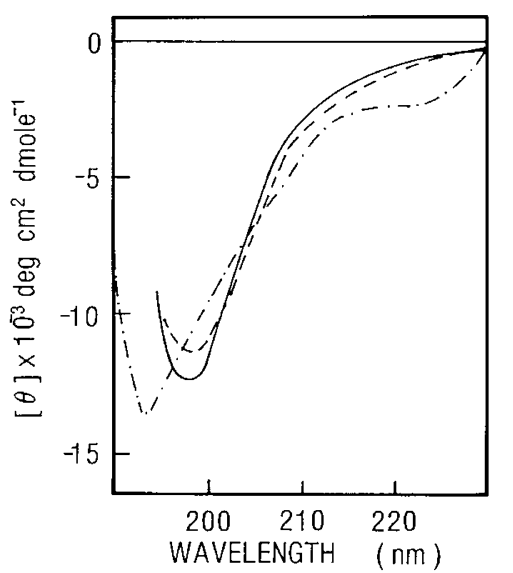

Fig. 5. The CD spectra for normal (-) and CF (---) salivary kallikreins in $0.02 \mathrm{M}$ phosphate buffer. $\mathrm{pH}$ 6.0. The data for normal enzyme, given in Table 111, were used to plot the curve (-.-.-) which represents the closest fit.

Table 3. Secondary structures of salivary kallikreins

\begin{tabular}{lcccc}
\hline \multicolumn{1}{c}{ Preparations* } & $\alpha$-Helix $\dagger$ & Pleated & & \\
\hline Normal enzyme & 0 & 41 & 15 & 44 \\
Normal enzyme in SDS & 0 & 51 & 8 & 41 \\
CF enzyme & 0 & 38 & 13 & 49 \\
\hline
\end{tabular}

* Enzyme solutions in $0.02 \mathrm{M}$ phosphate buffer $\mathrm{pH} 6.0$, and in phosphate buffer with $0.3 \%(\mathrm{w} / \mathrm{v})$ SDS.

$\uparrow$ Data are in percents and have been computed from the curves shown in Figure 5.

Table 4. Enzymatic properties of salivary kallikreins

\begin{tabular}{|c|c|c|}
\hline & CF enzyme & Normal enzyme \\
\hline Optimum activity* & $\mathrm{pH} 8.0-8.5$ & pH $8.0-8.5$ \\
\hline $\mathrm{K}_{\mathrm{m}}$ & $0.4 \mathrm{mM}$ & $0.4 \mathrm{mM}$ \\
\hline$V_{\max }$ & $\begin{array}{l}20 \mu \mathrm{mol} / \mathrm{min} / \\
\mathrm{mg}\end{array}$ & $\begin{array}{l}21 \mu \mathrm{mol} / \mathrm{min} / \\
\mathrm{mg}\end{array}$ \\
\hline $\mathrm{k}_{\text {cat }}$ & $13 s^{-1}$ & $14 \mathrm{~s}^{-1}$ \\
\hline Azocasein $(1 \mathrm{mg} / \mathrm{ml})$ & Not digested & Not digested \\
\hline $\begin{array}{l}\text { Soybean and lima bean tryp- } \\
\text { sin inhibitors }\end{array}$ & Inhibition $<2 \%$ & Inhibition $<2 \%$ \\
\hline Pancreatic trypsin inhibitors & Inhibition >98\% & Inhibition $>98 \%$ \\
\hline $\begin{array}{l}\text { Diisopropyl fluorophos- } \\
\text { phate } \dagger\left(10^{-5} \mathrm{M}\right)\end{array}$ & Inhibition $>80 \%$ & Inhibition $>80 \%$ \\
\hline $\begin{array}{l}\text { Drop in blood pressure when } \\
10 \mu \mathrm{g} \text { enzyme is intrave- } \\
\text { nously injected in a rabbit } \\
(\mathrm{mm} \mathrm{Hg})+\end{array}$ & $10 \mathrm{~mm}$ & $10 \mathrm{~mm}$ \\
\hline
\end{tabular}

* BAEE was used for substrate. Activities were measured with about 5-10 $\mu$ g enzyme per millimeter.

$\dagger$ Diisopropyl fluorophosphate is less effective for kallikrein than for trypsin. At pH 8.0 the activity of kallikrein is more quickly restored than that of trypsin when the solutions are dialyzed at $\mathrm{pH} 8.0$.

$\ddagger$ This test was carried out as described in Reference 21 .

numbers. Because of the uneven contents of the residues in the proteins the analyses are less accurate than is normally the case, and especially the sulfur-containing amino acids were difficult to determine. The amino acid compositions indicate low isoelectric points for the salivary kallikreins. This has been confirmed by isoelectric focusing of the normal and CF kallikreins which gave values of $\mathrm{pI}=4.00 \pm 0.08$ for both. Isoelectric focusing has also confirmed that the enzymes are pure.

The corrected intrinsic fluorescence spectra of the CF and normal salivary kallikreins are identical. Although the spectra show only one broad peak, calculations have shown that two

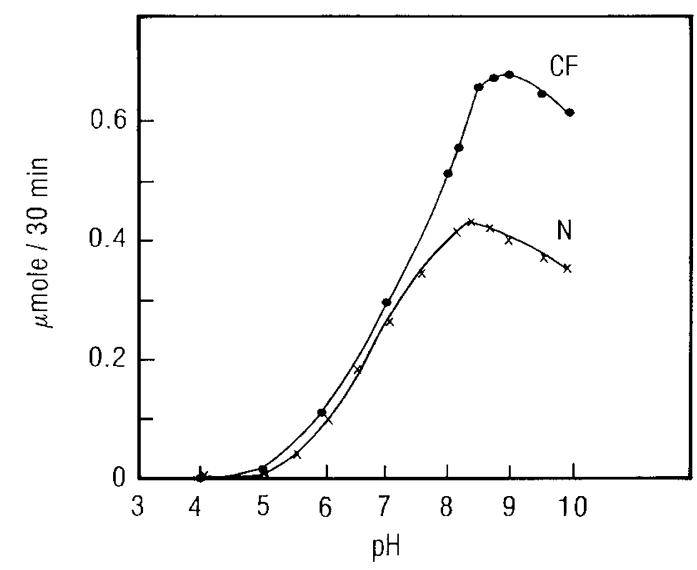

Fig. 6. The $\mathrm{pH}$ rate profiles for normal and $\mathrm{CF}$ salivary kallikreins. Aliquots of the enzymes were added to $0.6 \mathrm{mM}$ BAEE in $0.1 \mathrm{M}$ phosphate buffer $\mathrm{pH} 5.0$ to 8.0 and $0.1 \mathrm{M}$ Tris- $\mathrm{HCl}$ buffers $\mathrm{pH} 8.0$ to 10.0 . The reactions were followed at $37^{\circ} \mathrm{C}$ with a Cary model 14 recording spectrophotometer.

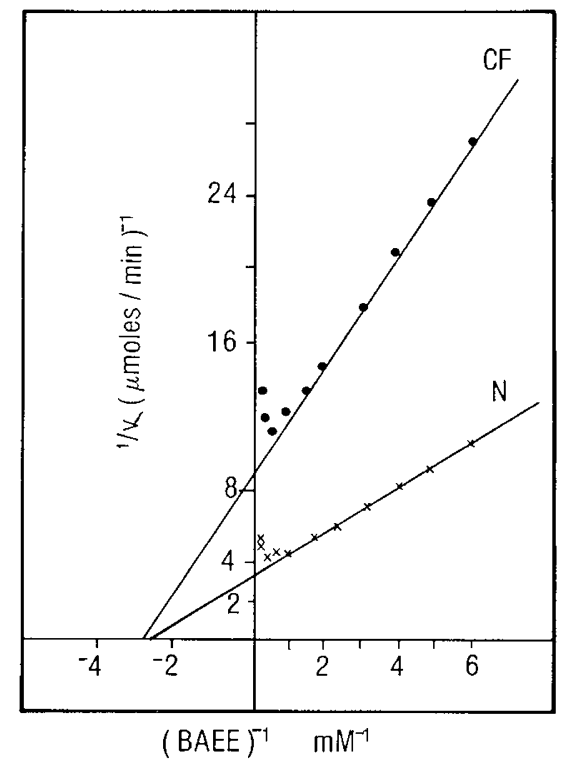

Fig. 7. Lineweaver-Burk plots for the hydrolysis of BAEE in $0.1 \mathrm{M}$ Tris- $\mathrm{HCl} \mathrm{pH} 8.0$ at $37^{\circ} \mathrm{C}$.

different fluorophores, presumably tyrosine and tryptophan, contribute to the emissions. The quantum yield of the CF enzyme is exactly the same as that of the normal salivary kallikrein.

The CD spectra of the enzymes are rather unusual because they show very little ellipticity at wavelengths above $210 \mathrm{~nm}$. This indicates very little $\alpha$-helix structure in the enzymes. Even at the extrema, at $197 \pm 1 \mathrm{~nm}$, the observed ellipticities are low. The experimental error in the measured ellipticities is therefore between 10 and $15 \%$. The $C D$ data have been analyzed by the method of Chang et al. (20) and the results indicate that the enzymes have indeed no $\alpha$-helical structure. Because of the fact that the three remaining basis spectra (thus those for the pleated sheet, $\beta$-turns, and unordered polypeptide chains) are less reliable, the data given in Table 3 should be interpreted with caution, especially since the calculated curve does not exactly fit the observed spectra. However, despite these reservations it is clear that the pleated sheet is the major structure in CF as well as in normal salivary kallikrein.

The enzymatic properties of the CF salivary kallikrein are the same as those of the normal enzyme. Although the kallikreins are likely to be serine proteases, as demonstrated by their inhibitions by diisopropyl fluorophosphate, no evidence has yet been 
found for an acyl-enzyme intermediate. The initial hydrolysis of the artificial substrate BAEE is linear with time. The $\mathrm{pH}$ rate profiles are not exactly bell-shaped as they only show a minor drop in activity at high $\mathrm{pH}$ values. Substrate inhibition is observed with BAEE at $\mathrm{pH} 8.2$ even if carefully purified substrate is used. The inhibitions at high BAEE concentrations are identical for the normal and CF enzyme. Since we have observed that polylysine also lowers the enzymatic activity it is believed that the substrate inhibition is caused by interactions on secondary binding sites. The presence of such sites could explain the fact that the $\mathrm{pH}$ rate profiles are not bell-shaped, because a decrease in BAEE affinity at these sites would obscure the reduction in arginine esterase activity at high $\mathrm{pH}$. Regardless of the mechanism of the substrate inhibition its effect seems to be small at low concentrations of BAEE. Thus linear LineweaverBurk plots are still observed at low substrate concentrations. The kinetic parameters calculated from these plots for normal and CF kallikreins are almost identical, despite the fact that long extrapolations are required which means that the results could be somewhat less reliable.

Thus our study shows that salivary kallikrein is present at the same level in $\mathrm{CF}$ saliva as in normal saliva and that it has very similar physicochemical properties. $\mathrm{CD}$ measurements attest to identical secondary structures while the intrinsic fluorescence indicates similar conformations. Furthermore the enzymatic properties of the CF salivary kallikrein are the same as those of the normal enzyme. It is therefore concluded that the salivary kallikrein in CF is not defect and that its activity is quite normal.

Acknowledgments. The authors acknowledge the financial support of the Canadian Cystic Fibrosis Foundation.

We like to thank Dr. C. T. Gillespie and the staff of the CF clinic at the I.W.K. Hospital for Children for their kind cooperation.

We also like to thank Ms. Carolyn Patterson for her help with the biological assays and Ms. Lisa Laskey for her technical help.

\section{REFERENCES}

1. Handwerger S. Roth J. Gorden P. di Sant'Agnese PA 1968 Unusual insulin secretion characteristic of cystic fibrosis of the pancreas. Pediatr Res 2: 295
2. Mangos JA, Barsman GJ, Martinez JR, Rennert OM 1976 Physiology and pharmacology of secretion and cystic fibrosis. In: Mangos JA, Talamo RC (eds) Cystic Fibrosis: Projections into the Future. Stratton Intercontinental Medical Book Corp, New York, pp 311-336

3. Wiesmann UN, Boat TF, di Sant'Agnese PA 1973 Flow-rates and electrolytes in minor-salivary-gland saliva in normal subjects and patients with cystic fibrosis. Lancet 2:510-512

4. Dann LG, Blau K 1978 Exocrine-gland function and the basic biochemical defect in cystic fibrosis. Lancet 2:405-407

5. Hallinan F 1981 Altered regulation of a proteinase mediated primary secretion processing system as the basic defect in cystic fibrosis. Med Hypotheses 7:793-800

6. Catanzaro OL, Seeber AM, Beraldo WT 1978 Possible relationship between salivary kallikrein and water-Na-K secretion stimulated by titustoxin (TsTx). Adv Exp Med Biol 120A:451 -454

7. Manning DC, Snyder SH, Kachur JF, Miller RJ, Field M 1982 Bradykinin receptor-mediated chloride secretion in intestinal function. Nature 299:256259

8. Fujimoto Y, Moriya H, Moriwaki C 1973 Studies on human salivary kallikrein: isolation of human saljvary kallikrein. J Biochem 74:239-246

9. Modeer T 1977 Characterization of kallikrein from human saliva isolated by use of affinity chromatography. Acta Odontol Scand 35:31-39

10. Hofmann W, Junk A, Geiger R 1983 Human tissue kallikrein: isolation and characterization of human salivary kallikrein. Hoppe-Seyler's Z Physiol Chem 364:425-432

11. Wong RSC, Madapollimattam G, Bennick A 1983 The role of glandular kallikrein in the formation of salivary proline-rich protein $A$ by cleavage of a single bond in salivary protein C. Biochem $\mathrm{J} 211: 35-44$

12. Hare ER, Verpoorte JA 1985 The purification of kallikrein from human whole saliva. Int J Biochem (in press)

13. Bradford MM $1976 \mathrm{~A}$ rapid and sensitive method for the quantitation of microgram quantities of protein utilizing the principle of protein-dye bincling. Anal Biochem 72:248-254

14. Schwert G. Takenaka Y 1955 A spectrophotometric determination of trypsin and chymotrypsin. Biochim Biophys Acta 16:570-575

15. Hirs CHW 1967 Performic acid oxidation. Meth Enzymol 11:197-199

16. Goodwin TW, Morton RA 1946 The spectrophotometric determination of tyrosine and tryptophan in proteins. Biochem J 40:628-632

17. Melhuish WH 1962 Calibration of spectrofluorimeters for measuring corrected emission spectra. J Opt Soc Am 52:1256-1258

18. Chen RF 1966 Reduction of light scatter in fluorometry by the use of horizontally polarized excitation. Anal Biochem 14:497-499

19. Weber G 1961 Enumeration of components in complex systems by fluorescence spectrophotometry. Nature 190:27-29

20. Chang CT, Wu C-SC, Yang JT 1978 Circular dichroic analysis of protein conformation: inclusion of the $\beta$-turns. Anal Biochem 91:13-31

21. Hare ER, Verpoorte JA 1982 The purification and partial characterization of human salivary kallikrein. Biochim Biophys Acta 709:65-72 